\title{
NUMERICAL STUDY OF GAS-PHASE FLOW IN A CYCLONE SEPARATOR
}

\author{
YA-PING SHI \\ College of Engineering, Shantou University \\ Shantou, Guangdong, China \\ 14ypshi@stu.edu.cn \\ BIAO QU \\ College of Engineering, Shantou University \\ Shantou, Guangdong, China \\ 13bqu@stu.edu.cn \\ SHAN HUANG \\ College of Engineering, Shantou University \\ Shantou, Guangdong, China \\ 14shuang@stu.edu.cn \\ XIAO-DONG NIU \\ College of Engineering, Shantou University \\ Shantou, Guangdong, China \\ xdniu@stu.edu.cn
}

Published 22 June 2016

To investigate separation efficiency of a cyclone separator at different operating parameters, in this paper we use Fluent software to numerically study the three dimensional gas-solid two-phase flows in the cyclone separator. The present work mainly consists four parts. Firstly we investigates the accuracy of different turbulent models including the standard k- $\varepsilon$ model, RNG k- $\varepsilon$ model, Realizable k- $\varepsilon$ model and Reynolds stress equation model (RSM), and finds that the RSM turbulence model gives a good comparison between the numerical results and the experimental results. Secondly, the gas phase flow rate, pressure, and turbulent distribution in the cyclone separator are explored numerically in detail with the RSM model. Thirdly, on the base of the gas flow results, gas-solid two phase flows in the cyclone separator are studied by coupling the random trajectory model in the Lagrangian coordinates so that the particle trajectories in separator are displayed. Finally, effects of particle size and velocity at the cyclone separator inlet on the separation efficiency are analyzed. Numerical results show that when the particle velocity is higher and particle size is larger at the inlet, the separation efficiency is better. However, when the particle velocity and size approach their threshold values, the separation efficiency will not change.

Keywords: Cyclone separator; numerical simulation; gas-solid two phase flow; separation performance.

This is an Open Access article published by World Scientific Publishing Company. It is distributed under the terms of the Creative Commons Attribution 3.0 (CC-BY) License. Further distribution of this work is permitted, provided the original work is properly cited. 


\section{Introduction}

So far cyclone development has more than one century. As people pay more attention to environmental protection, cyclone separation is widely used in industry because of its low cost and good effect of operation in petrochemical, environmental pollution and dust the molding plant.

However, with nowadays rapid development, a simple cyclone separator has been unable to meet the demand of the rapid development of technology and working conditions, as the uncertainty and gas flow of flow field motion in the cyclone separator with the collision, crushing and other physical phenomenon is complicated. In order to allow the separator to produce better results for dust separation and consume less power energy, we should have a deep understanding of the separator's principles and rules. Moreover, for the sake of improving the efficiency, structures and optimization of its shape and size, it is very necessary for us to study the trajectory of the cyclone flow field distribution inside and solid particles, giving a reference value of cyclone design at the same time.

\section{Physical Model Analysis}

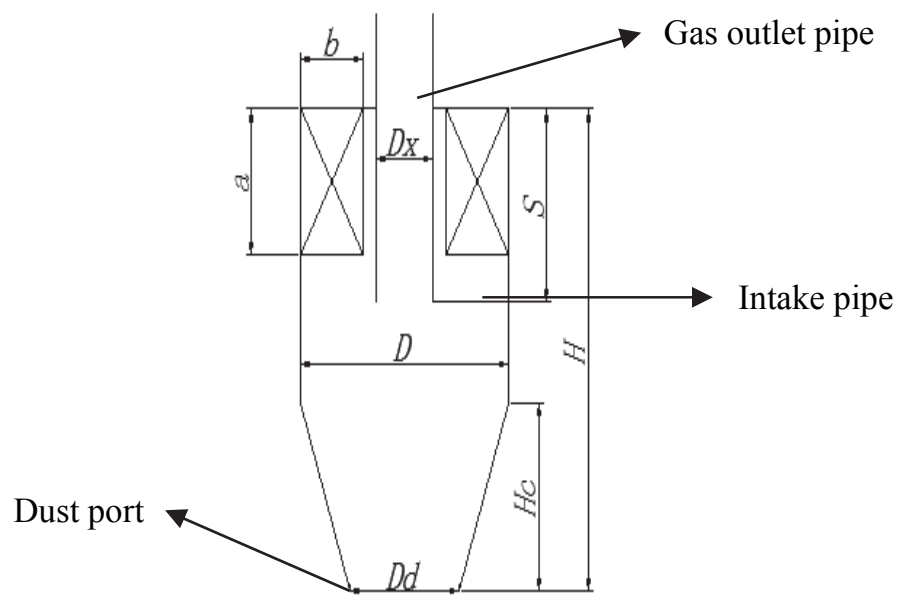

Fig. 1. Physical computational model.

Table 1. Numerical simulation of the size parameters of the separator.

\begin{tabular}{ll}
\hline Symbol description & parameter $(\mathrm{mm})$ \\
\hline Dust outlet diameter $D d$ & 72.5 \\
The height from cone to capture port $H c$ & 285 \\
Intake pipe height $c \times d$ & $95 \times 38$ \\
Insertion depth of exhaust pipe $S$ & 95 \\
Exhaust pipe diameter $D x$ & 64 \\
Total height of cyclone separator $H$ & 760 \\
Cylinder diameter of cyclone separator $D$ & 190 \\
\hline
\end{tabular}


Generally, the cyclone separator is made up of the intake pipe, exhaust pipe, dust outlet, cylinder and cone cylinder, etc. The relevant dimensions of the cyclone separator are shown as Table 1.

\subsection{Computational methods}

In this paper we use Fluent software to numerically study the three dimensional gas-solid two-phase flows in the cyclone separator.

For incompressible fluid, the form of Reynolds stress model (RSM) can be written as

$$
\begin{aligned}
& \frac{\partial\left(\rho \overline{u_{i}^{\prime} u_{j}^{\prime}}\right)}{\partial t}+\frac{\partial\left(\rho u_{k} \overline{u_{i}^{\prime} u_{j}^{\prime}}\right)}{\partial x_{k}}=-\frac{\partial}{\partial x_{k}}\left[\rho \overline{u_{i}^{\prime} u_{j}^{\prime} u_{k}}+\overline{p^{\prime} u_{i}^{\prime}} \delta_{k j}+\overline{p^{\prime} u_{i}^{\prime}} \delta_{i k}\right] \\
& +\frac{\partial}{\partial x_{k}}\left[\mu \frac{\partial}{\partial x_{k}} \overline{u_{i}^{\prime} u_{j}^{\prime}}\right]-\rho\left(\overline{u_{i}^{\prime} u_{j}^{\prime}} \frac{\partial u_{i}}{\partial x_{k}}+\overline{u_{i}^{\prime} u_{k}^{\prime}} \frac{\partial u_{i}}{\partial x_{k}}\right) \\
& -\rho \beta\left(g_{i} \overline{u_{j}^{\prime} \theta}+\overline{g_{i} u_{i}^{\prime} \theta}\right)+\overline{p^{\prime}\left(\frac{\partial u_{i}^{\prime}}{\partial x_{j}}+\frac{\partial u_{j}^{\prime}}{\partial x_{i}}\right)} \\
& -2 \mu \overline{\frac{\partial u_{i}^{\prime}}{\partial x_{k}} \frac{\partial u_{j}^{\prime}}{\partial x_{k}}}-2 \rho \Omega_{k}\left(\overline{u_{j}^{\prime} u_{m}^{\prime} e_{i k m}}+\overline{u_{i}^{\prime} u_{m}^{\prime}} e_{j k m}\right) \text {. }
\end{aligned}
$$

The kinetic energy and dissipation rate equation of the RSM model is defined as

$$
\begin{gathered}
\frac{\partial(\rho k)}{\partial t}+\frac{\partial\left(\rho k u_{i}\right)}{\partial x_{i}}=\frac{\partial}{\partial x_{j}}\left[\left(\mu+\frac{\mu_{t}}{\sigma_{k}}\right) \frac{\partial k}{\partial x_{j}}\right]+\frac{1}{2} P_{i j}-\rho \varepsilon . \\
\frac{\partial(\rho \varepsilon)}{\partial t}+\frac{\partial\left(\rho k u_{i}\right)}{\partial x_{i}}=\frac{\partial}{\partial x_{j}}\left[\left(\mu+\frac{\mu_{t}}{\sigma_{\varepsilon}}\right) \frac{\partial \varepsilon}{\partial x_{j}}\right]+C_{1 \varepsilon} \frac{1}{2} P_{i j}-C_{2 \varepsilon} \rho \frac{\varepsilon^{2}}{k} .
\end{gathered}
$$

where $P_{i j}$ is the production term of shear stress and $\mu_{t}$ is turbulent viscosity. For this case, $C_{1 \varepsilon}=1.44 、 C_{2 \varepsilon}=1.92 、 C_{\mu}=0.09 、 \sigma_{k}=1.0$.

Reynolds stress simulation can get higher prediction accuracy to the strong rotating flow, streamline bending, swirl and so on, which is the most sophisticated production model in FLUENT.

\subsection{Solution of particle model}

The movement of individual particles in the flow field of the separator is mainly influenced by the following force: drag force, Saffman lift force, Basset force, Magnus force, added mass force, gravity, pressure gradient force and so on. As in the present work the particles are mainly influenced by fluid drag force, Saffman force and mass 
force in the internal movement of separator, the particles in the form of the equilibrium equations in Cartesian coordinates can be written

$$
\begin{gathered}
\frac{d u_{p}}{d t}=F_{D}\left(u-u_{p}\right)+\frac{g_{x}\left(\rho_{p}-\rho\right)}{\rho_{p}}+F_{x s} . \\
\frac{d v_{p}}{d t}=F_{D}\left(v-v_{p}\right)+\frac{g_{y}\left(\rho_{p}-\rho\right)}{\rho_{p}}+F_{y s} . \\
\frac{d w_{p}}{d t}=F_{D}\left(w-w_{p}\right)+\frac{g_{z}\left(\rho_{p}-\rho\right)}{\rho_{p}}+F_{z s} .
\end{gathered}
$$

where

$$
\frac{d x}{d t}=u_{p} \quad \frac{d y}{d t}=v_{p} \quad \frac{d z}{d t}=w_{p} .
$$

$\rho_{p}, \rho$ are the density of air and particle, $\mathrm{km} / \mathrm{m}^{3}$

$u, v, w$ are the component velocity of gas phase flow in the axes of X,Y,Z, $m / s$

$u_{p}, v_{p}, w_{p}$ are the component velocity of particle phase in the axes of X,Y,Z, $m / s$

$g_{x}, g_{y}, g_{z}$ are gravity acceleration in the axes of X,Y,Z, $\mathrm{m} / \mathrm{s}^{2}$

$F_{x s}, F_{y s}, F_{z s}$ are others forces in the axes of X,Y,Z, $N$

\subsection{Cyclone separation efficiency}

In the operation of cyclone separator, there are three parts of the particles: particles from the air inlet pipe particle entering the inner of the separator, the particles collected in the dust collecting port by the device and the particles escaping from the exhaust pipe. So we can obtain balance equation between the particle mass from cyclone separator:

$$
M_{f}=M_{c}+M_{e} .
$$

Now the total efficiency $\eta$ is defined by

$$
\eta=\frac{M_{c}}{M_{f}}=1-\frac{M_{e}}{M_{f}}=\frac{M_{c}}{M_{c}+M_{e}} .
$$

where $M_{f}$ the quality of particles entering cyclone separator is, $M_{c}$ is the particle quality of dust collecting port and $M_{e}$ is the particle quality escaping from chaff outlet.

Separation efficiency of the cyclone separator is the most commonly used parameter in evaluation index. For a particular cyclone separation performance, index is not comprehensive, because it does not only depend on the cyclone separator, but on particle size distribution and particle concentration factors. 


\subsection{Boundary condition}

Table 2. Boundary setting conditions of cyclone separation.

\begin{tabular}{ll}
\hline Position of cyclone separation & Boundary condition \\
\hline Exhaust pipe port & Outflow $=1$ \\
$\begin{array}{l}\text { Dust removal } \\
\text { The others }\end{array}$ & Outflow $=0$ \\
\hline Note: 0 and 1 stand for flow rate. Where 0 indicates that the gas flow can go \\
through the exhaust pipe and 1 cannot go through the dust removal. \\
Table 1 (Continued)
\end{tabular}

\section{Results Analysis}

\subsection{Position analysis}
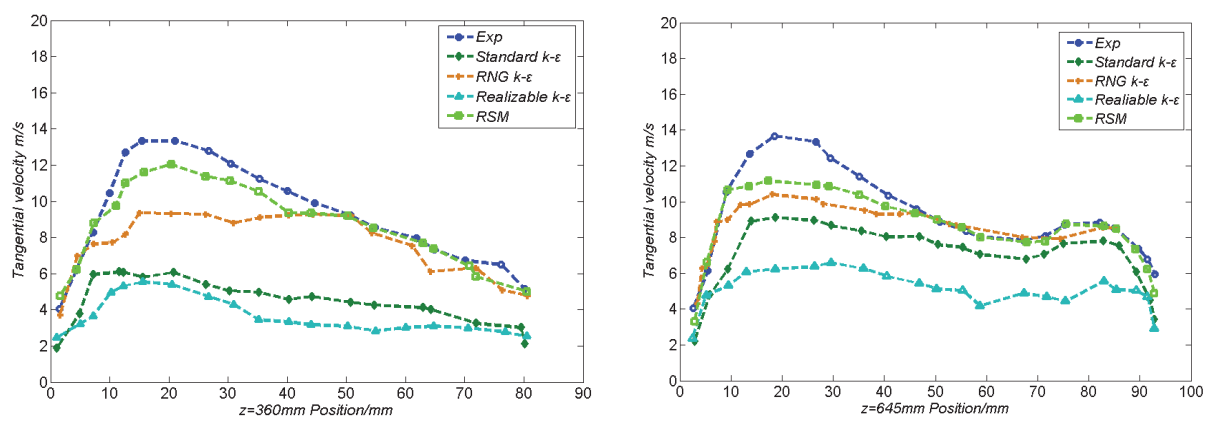

Fig. 2. Tangential velocity distribution of height plane $Z=360 \mathrm{~mm}$ and $645 \mathrm{~mm}$.

Through the comparison of the above two turbulence models of numerical simulation results, we can draw a conclusion that RSM force model is the closest between speed and the experimental results under the stress model numerical simulation, which can best reflect the cyclone separator of gas phase flow characteristics; Errors are respectively, RSM model error is $10 \%, 17 \%$ of RNG model, $46.4 \%$ of the standard error model and realizable model error $56.4 \%$. 


\subsection{Analysis of Velocity Chart}

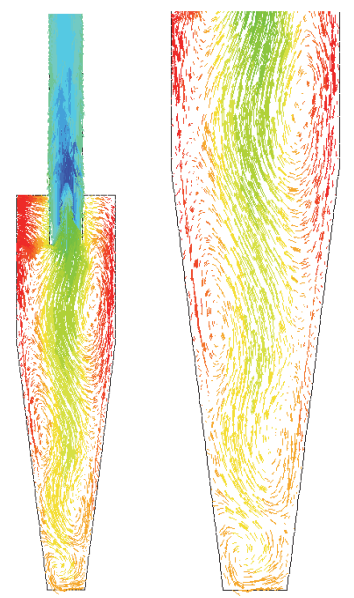

Fig. 3. Plane $X=0 \mathrm{~mm}$. Velocity vector diagram and its enlarged image.

As shown in Fig. 3, it is found that rotational gas flow occurs near the cyclone wall when gas flow enters the cyclone separator. Under the influence of bottom wall of the dust discharge outlet, in the cyclone collector's center region, an up gas flow stream is formed, and a down flow appears near the cyclone separator wall. Due to the conical shape at bottom part of the cyclone separator, gas flow gradually accelerates down to this part and more secondary vortex flows are formed. In addition, as the flow is at high Reynolds number, an oscillation of the central up flow stream is clearly observed near the conical region of the separator.

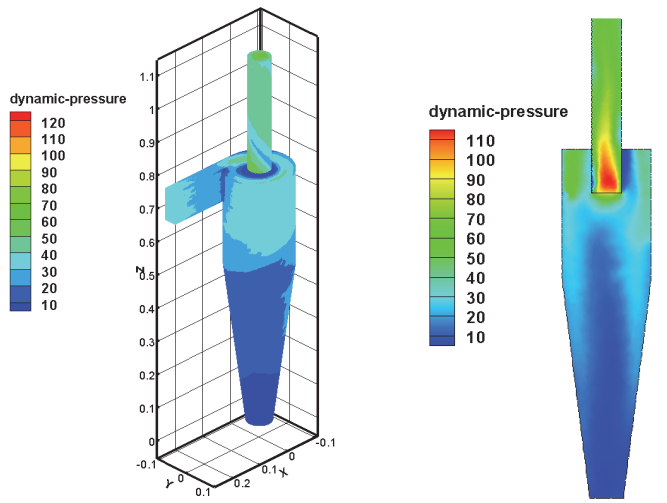

Fig. 4. Pressure distribution.

Figure 4 shows the dynamic pressure distribution in the cyclone separator. Corresponding to Fig. 3, in which the flow velocity is small in the inlet of the gas intake pipe and higher in the separator, the dynamic pressure in the inlet region of the gas intake pipe is high and low in the separator as shown in Fig. 4. 


\section{Separation Performance}

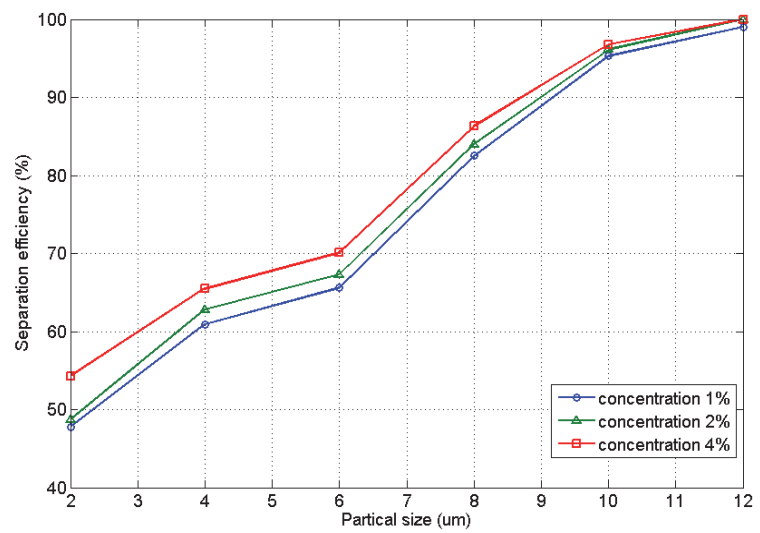

Fig. 5. Separation efficicency of particles at different inlet concentration of particles.

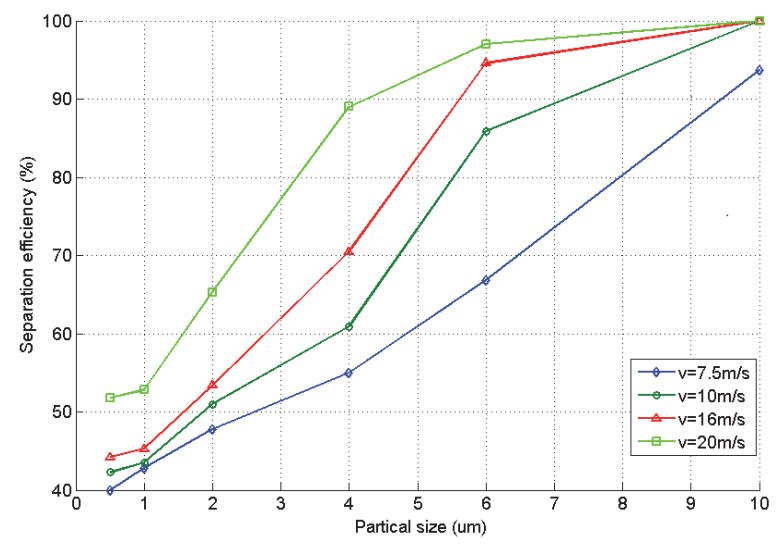

Fig. 6. Separation efficiency of particles at different inlet velocity.

Figures 5 and 6 show the separation efficiency varies with the particle size at different particle concentrations and inlet flow velocities. Observed from Figs. 5 and 6, with the increase of particle size, the separation efficiency of cyclone separator almost linearly increases. And increasing particle concentration, separation efficiency increases when the particle size is smaller than $10 \mu \mathrm{m}$ and has not too much change for the larger particle size. However, it is clearly observed that the separation efficiency increases with increasing the inlet flow velocity. But it is not clear whether the efficiency is further increased or not at the let velocity higher than $10 \mathrm{~m} / \mathrm{s}$ for the particle size larger than $10 \mu \mathrm{m}$, which needs further study. 


\section{Conclusions}

As shown above, based on the analysis of the RSM turbulence model, it will form complex flows at the bottom part of the cyclone separator. And the dynamic pressure in the inlet region of the gas intake pipe is higher and low in the separator. With the increase of particle size, the separation efficiency of cyclone separator almost linearly increases when the particle size is smaller than $10 \mu \mathrm{m}$.

\section{References}

1. C. Bhasker, Flow simulation in industrial cyclone separator. Advances in Engineering software, 41 (Mississippi, America 2010).

2. Hai-hong Zhang, Numerical simulation of flow field and separation performance of cyclone separator. D 11 (Zhengzhou, China 2004).

3. Hai-gang Wang, Numerical simulation and experimental study on the gas-particle two-phase flows in cyclone separations. (Beijing, China, 2003).

4. Crowe C.T., Sharma, M.P., Stock D.E., Particle-Source-In Cell (PSI CELL) Model for GasDrop Flows. Trans. ASME, J. Fluids Eng. (1977).

5. Liang-shih Fan, Chao Zhu, Principles of Gas-Solid Flows. Cambridge University Press, (1997). 